\title{
SER UNO MISMO. REPENSANDO LA AUTONOMÍA Y LA RESPONSABILIDAD COMO COORDENADAS DE LA EDUCACIÓN ACTUAL
}

\author{
Being one's self. Rethinking autonomy and responsibility \\ as mainstays in today's education
}

Être soi-même. Repenser l'autonomie et la responsabilité
en tant que coordonnées de l'éducation actuelle

Marta Ruiz Corbella*, Antonio Bernal Guerrero***, Fernando Gil CANTERO**** y Juan EsCÁMEZ SÁNCHEZ*****

* Universidad Nacional de Educación a Distancia. Facultad de Educación. Departamento de Teoría de la Educación y Pedagogía Social. C/ Juan del Rosal, 14. Ciudad Universitaria. 28040 Madrid. Correo-e: mruiz@edu.uned.es

* Universidad de Sevilla. Facultad de Ciencias de la Educación. Departamento de Teoría e Historia de la Educación y Pedagogía Social. C/ Pirotecnia, s/n. 41013 Sevilla.Correo-e: abernal@us.es **** Universidad Complutense de Madrid. Facultad de Educación. Centro de Formación del Profesorado. Departamento de Teoría e Historia de la Educación. C/ Rector Royo Villanova, s/n. Ciudad Universitaria. 28040 Madrid. Correo-e: gcantero@edu.ucm.es ${ }^{* * * * * *}$ Universidad de Valencia. Facultad de Filosofía y Ciencias de la Educación. Departamento de Teoría de la Educación. Avada Blasco Ibáñez, 31. 46010 Valencia.Correo-e: juan.escamez@uv.es

Fecha de recepción: marzo de 2012 Fecha de aceptación definitiva: julio de 2012 Biblid [(1130-3743) 24, 2-2012, 59-81] 


\section{RESUMEN}

Uno de los objetivos clave de la educación del siglo XxI es la formación en la autonomía y la responsabilidad. La primera, como garantía de la configuración de la identidad de cada individuo que conlleva, a su vez, un compromiso ante uno mismo, ante los otros y lo otro. La segunda, como respuesta a nuestra capacidad de comprometernos. Para ello será necesario sumergirnos, en primer lugar, en los conceptos de individualidad y libertad, ejes del despertar del sujeto y del desarrollo de su identidad. En segundo lugar, plantear los derechos y deberes de toda persona en cualquier escenario de interacción, puntos de referencia permanentes, para abordar, en tercer lugar, la responsabilidad, clave para la construcción de la identidad moral de cada individuo. En definitiva, formar a cada uno para que sea capaz de vivir conforme a su propia identidad, comprometido con un proyecto vital común con los otros y lo otro, en un mundo donde múltiples miradas son posibles.

Palabras clave: autonomía, responsabilidad, identidad moral, yo, educación, teoría de la educación.

\section{SUMMARY}

One of the main goals of education in the $21^{\text {st }}$ Century is developing students' autonomy and responsibility. The first is to guarantee the shaping of each individual's identity, which at the same time entails a pledge to one's self, to others and to the surrounding reality. The second is in response to our ability to make commitments. To this end we must first immerse ourselves in the concepts of individuality and freedom, which are at the heart of the subject's awakening and the development of his or her identity. Second, we must outline to all people their rights and duties which will act as permanent reference points that are valid for any situation of interaction. This will finally allow us to address the idea of responsibility, a key factor in forming the moral identity of each individual. In short, the idea is to shape people so that they can live in accordance with their own identity and make a commitment to a common future with other people and other issues and realities, in a world where multiple viewpoints are possible.

Key words: autonomy, responsibility, moral identity, self, education, theory of education.

\section{SOMMAIRE}

L'un des objectifs clés de l'éducation du $\mathrm{xxI}^{\mathrm{e}}$ siècle est la formation dans l'autonomie et la responsabilité. La première, comme une garantie de la configuration de l'identité de chaque individu qui entraîne à son tour, un engagement face à soi-même. La seconde comme une réponse à notre capacité de nous engager. Pour cela, il est nécessaire, en premier lieu, de nous immerger dans les concepts de l'individualité et de la liberté, axes du réveil du sujet et du développement de son identité. En deuxième lieu, établir les droits et devoirs de toute personne dans n'importe quel scénario d'interaction, points de référence permanents, pour aborder, en troisième lieu, la responsabilité, clé pour la construction de l'identité morale de chaque individu. En définitive, former chacun pour qu'il soit capable de vivre 
conformément à sa propre identité, engagé dans un projet vital commun avec les autres et l'autre dans un monde où plusieurs regards sont possibles.

Mots clés: l'autonomie, responsabilité, identité morale, moi, l'éducation, théorie de l'éducation.

\section{INTRODUCCIÓN}

A lo largo de las últimas décadas el debate sobre la educación ha estado centrado en la construcción y consolidación de escenarios democráticos, interculturales e inclusivos, como ejes vertebradores de esta nueva realidad. Muchos han sido los autores y actores que han trabajado en estos temas que enmarcan la educación del siglo XXI, y muchas han sido las propuestas realizadas y las experiencias llevadas a cabo. Gracias a todas ellas se ha ido avanzando en la configuración de la persona que queremos en nuestras sociedades occidentales, ahora bien, a lo largo de todo este proceso se echa en falta una mayor reflexión sobre los principios clave que sustentan esta personalidad democrática. De entre todos ellos, destacamos la autonomía y la responsabilidad como conceptos esenciales que enraízan al ciudadano de nuestro siglo. Ambos presentan una rica historia: la autonomía destacando como uno de los objetivos clave y eje prioritario del discurso dirigido a la consolidación de la ciudadanía democrática. Desde esta exigencia se ha ido deslizando, de forma suave y necesaria, el reclamo de la autonomía personal y social, como garantía de todo espacio de convivencia y factor esencial para la participación de todos los individuos en su construcción, consolidación y permanencia en el tiempo, con el que contrae, necesariamente, obligaciones de lealtad (Cortina, 2001). En este sentido, se entiende que la autonomía personal no tenga sentido sin la autonomía social, y viceversa. Ahora, ésta implica un compromiso, una responsabilidad ante uno mismo y ante los otros y lo otro, que se evidencia en las elecciones, las decisiones, las creencias, las acciones, las preferencias, etc., de cada uno (Cuypers, 2010). En todas ellas es capaz de explicar el porqué de cada una de éstas, de concatenarlas con las otras decisiones, elecciones o acciones que ha llevado a cabo y asumir sus consecuencias. En definitiva, es capaz de responder de sí mismo, de cada una de las personas y de los elementos que le configuran como tal. En suma, de su identidad.

Pero no sólo personas, también organizaciones. Gestionar cualquier institución bajo los ejes de la autonomía es uno de los puntos esenciales de las organizaciones. Si atendemos a las instituciones educativas, la autonomía ha sido el principio que ha envuelto la política europea en las dos ultimas décadas y el corazón de las reformas de la mayoría de estas naciones en todos los niveles educativos, en aras de fortalecer su democratización y potenciar la calidad de la educación. Autonomía que está reclamando cada vez con mayor fuerza la responsabilidad de estas organizaciones. 
En este sentido, si estamos apostando por el desarrollo y consolidación de una ciudadanía democrática, de acuerdo a la realidad en la que estamos insertos, con todas sus posibilidades y su problemática, es coherente y acertado pararnos a analizar y aportar una visión lúcida de cuál es su auténtico contenido y sentido. De ahí que debamos sumergirnos en la individualidad y la libertad como ejes del despertar del sujeto. Que abordemos la responsabilidad como clave para la construcción de la identidad moral de cada individuo, analizando, a su vez, el porqué de su ausencia en el discurso pedagógico de las últimas décadas. Que enseñemos a aprender a vivir, planteando los derechos y deberes en todo escenario de interacción. En definitiva, ser capaces de crear espacios de construcción del sujeto, que configuren identidades autónomas y responsables ante los deberes y derechos que detenta todo ciudadano y ciudadana de este milenio.

\section{LA LIBERTAD COMO CONDICIÓN NECESARIA DE LA AUTONOMÍA}

Vinculada a la idea que el hombre tiene de sí mismo, la importancia de la libertad se ha revalorizado en la medida en que se ha producido un renacimiento de la idea de sujeto. ¿Pero, qué podemos entender por libertad?, ¿a qué nos referimos cuando hablamos de libertad? La vieja polémica entre libertad y determinismo tal vez adquiere en la actualidad renovado vigor, sobre todo si se considera que el actual determinismo expande su tradicional visión, considerando tanto las leyes estrictas como las probabilistas y reconociendo la posibilidad de procesos caóticos.

Desde una perspectiva conceptual o analítica, se han realizado argumentaciones diversas a favor de la libertad. Espiguemos sucintamente algunas de ellas. Se ha argumentado la existencia de la libertad basada en las vivencias personales. Al decidir y actuar no nos sentimos causalmente determinados. Parece que nada acontecería si nos quedáramos esperando a que actúen las causas para observarlas. Pero quizás esto pueda explicarse por la propia disposición de nuestro sistema cognitivo. Evolutivamente, acaso hemos desarrollado disposiciones para la percepción causal de modo que podamos distinguir en los entornos naturales las relaciones causales que resultan útiles para la acción. Proverbialmente conocida es la teoría kantiana del conocimiento, para la cual la causalidad es una categoría de pensamiento y no podemos tener visiones exteriores que carezcan de definición espacio-temporal. Para conciliar libertad y determinación causal, Kant se refirió a ámbitos diferentes: el determinismo quedaba ligado al mundo fenoménico, mientras que la libertad se relacionaba con el mundo de las "cosas en sí" y se evidenciaba por la "razón práctica". Pero el sujeto que nos importa considerar, el sujeto que sea en sí, se encuentra dentro de las dimensiones espacio-temporales y se hace difícil concebir la libertad y la moral fuera del mundo empírico; por otra parte, nuestro pensamiento está transido de intereses propios y ajenos y se halla vinculado al ámbito fenoménico. También es posible realizar una propuesta superadora de las aparentemente inconciliables tesis de la libertad y el determinismo, bajo el influjo del último Wittgenstein. 
Oponer palabras y frases sobre la libertad y el determinismo no tiene sentido, pertenecen a juegos lingüísticos distintos y no pueden contradecirse. En la concepción de los juegos lingüísticos, las tesis de la libertad y del determinismo carecen de proposiciones sobre el mundo real. Sin embargo, parece que el lenguaje, aunque tenga muchas otras funciones además de representar la realidad, también parece apropiado para describir o exponer realidades, con lo que la solución del problema amparada en los juegos lingüísticos resulta cuestionable.

La mera discusión conceptual o lógico-analítica no parece contribuir decisivamente al esclarecimiento de si el ser humano es realmente libre o, dicho de otro modo, en qué sentido puede serlo. Posiblemente, la libertad tampoco es, o no sólo es, una trascendental, "noumenal", esencia metafísica, sino que podemos conjeturar razonablemente su consistencia en una serie de fenómenos observables y no directamente observables, pero inferibles y reconstruibles desde la observación (Fierro, 2002). Para aproximarse al estudio de la libertad del comportamiento del ser humano, posiblemente convenga centrarse en procesos de libertad en la acción humana tales como el proceso de decisión o elección entre alternativas, la activación y determinación intrínseca del agente en atención a su acción, el control efectivo, las expectativas y conciencia de control sobre los propios actos y sus consecuencias, así como aquellos procesos denominados de autorregulación.

Desde la perspectiva neurocientífica se nos brindan nuevas luces sobre el problema que nos ocupa. Aunque los resultados de la deliberación consciente estén significativamente limitados por una gran colección de predisposiciones inconscientes, de origen biológico y cultural, no podemos conformar el hábitat del ser humano sin una deliberación reflexiva y consciente (Damasio, 2010). En sistemas complejos, como son los neuronales, hay procesos que no están completamente determinados causalmente, dándose espacios "vacíos" entre ciertos estados del sistema. He aquí una puerta abierta a la argumentación de la libertad en el ser humano, fundada en esos "Vacíos", espacios para la intersección del ser uno mismo y la memoria, aquellos intersticios donde se mece nuestra identidad. Filosóficamente, a tales espacios "vacíos" se ha referido John Searle (2000) asociándolos al tradicional concepto de "libertad de volición", relativo a la facultad de determinar uno mismo los propios actos de voluntad, frente a la "libertad de acto", relacionada con poder hacer lo que se quiere.

\subsection{Ausencia de coacción y autodeterminación}

En general, podríamos decir que la libertad que apetecen las personas y cuya restricción o prohibición temen podría encuadrarse en lo que denominamos autodeterminación y ausencia de coacción. Incluso que nuestros deseos, motivaciones e inclinaciones puedan considerarse como causas no parece crearnos directamente un problema relevante. Sí nos lo crea, por ejemplo, la existencia de leyes que van contra nuestros intereses o el uso de la fuerza por otras personas para imponer determinadas condiciones que puedan reducir nuestra acción. Hay conciliación 
posible entre libertad y determinismo, si pensamos la libertad como ausencia de coacción y renunciamos a la idea de una libertad absoluta, probablemente una ilusión generada en nuestra cultura. En este sentido, resulta evidente que cuando tomamos decisiones estamos determinándonos, o sea, decidirse es tanto como autodeterminarse (Bernal, 2005). Aunque ésta incluya siempre limitaciones.

En efecto, nuestra experiencia de la libertad tiene relación con el hecho de que no pocas veces nos sentimos limitados, coartados. La naturaleza misma nos opone resistencia, nos presenta obstáculos, a la consecución de nuestras metas y nuestras capacidades son limitadas. Pero estas resistencias no dejan de ser algo lógico e insoslayable. Cuando nos sentimos, en cambio, coaccionados por otros seres humanos que nos subyugan, que amenazan nuestras posibilidades de acción, entonces nuestra libertad queda mermada, seriamente dañada. La libertad, entendida como "ausencia de coacción", ha caracterizado en líneas generales la evolución histórica de nuestra civilización. Esto es, ser libre vendría a significar "poder" hacer lo que se "quiere" sin que nadie lo impida (y, dando un paso más, sin hacer daño a nadie). Igualmente, puede formularse positivamente: la libertad se da cuando uno puede fijarse sus propios fines, es decir, cuando puede "autodeterminarse", cuando goza de "autonomía".

Mientras se trate de una coacción visible y claramente externa al agente, el concepto de libertad de coacción parece nítido. Ahora bien, si dentro del concepto de coacción se incluyen diferentes y poderosos modos de coacción o interferencia de nuestro comportamiento menos visibles o evidentes, la noción de libertad de coacción parece menos clara. Los determinantes políticos y económicos, así como la acción de otras personas, tornan problemática la libertad de acción del ser humano. Más aún, hay determinaciones externas que, paradójicamente, tratan de contribuir a la constitución de la persona como sujeto libre, como son las diversas prácticas educacionales, que comprenden un arco complejo desde menos a más coactivas. Recuérdese que Durkheim (1922), por ejemplo, ya nos advirtió de que no hay realmente educación que sea de verdad libre. Pensando en la dimensión social de la libertad, no es viable pensar en una ausencia absoluta de coacción, puesto que si muchos hacen todo lo que quieren, la libertad de los otros se restringe notablemente. Por eso, en filosofía política, se ha propuesto como razonable la exigencia de la libertad máxima de cada individuo compatible con la misma libertad para los demás (Schmücker y Steinvorth, 2002). Con lo cual, la coacción en algún grado parece socialmente necesaria para proteger la igualdad de la libertad. De modo que lo verdaderamente importante sería la "ausencia de coacción injustificada", o sea, de una coacción que restringe innecesariamente la libertad y no la protege.

También podemos hablar de una "coacción interior". Ciertamente, cuando una persona tiene control sobre sus actos, entendemos que puede hacer uso de su capacidad de razonar y de considerar puntos de vista morales; pero, cuando "pierde" ese control, ya sea momentáneamente o durante más tiempo, por una emoción desmedida o por una adicción, por ejemplo, la persona se halla sometida 
a una coacción interior, puesto que aunque tenga capacidad de deliberar, ésta no tiene influencia finalmente en la acción. Entonces, podríamos decir que tales actos no son libres. Pero también debemos considerar que algunas acciones, incluso las que parecen controladas, pueden estar también determinadas. En esta línea, aún tiene mucho que aportarnos la neurología de la conciencia sobre la relevancia de los procesos corporales mismos: "Es bastante posible, y en realidad probable, que lleguemos a darnos cuenta de que los procesos corporales, algunos ya conocidos, otros aún por descubrir, influyen en muchos niveles de nuestras experiencias conscientes" (Damasio, 2010, 394).

La libertad puede considerarse, en fin, como un modo de causalidad, una causalidad interna, propiedad de la conducta autodeterminada. De este modo, se pasa a una acepción positiva de la libertad: ya no se trata de ausencia de coacción o determinismo, sino de determinación y producción intrínseca del acto, además de espontaneidad, capacidad positiva y propia para actuar.

\subsection{La construcción de la identidad desde los márgenes de autonomía y responsabilidad}

Los científicos que investigan el cerebro no han localizado "yo" alguno en el mapa cerebral. Ningún filósofo contemporáneo eminente ha asegurado que el "yo" sea una substancia material con sede en el cerebro (Metzinger, 2003). Sin embargo, lejos de fantasías actuales sobre tal localización material de reminiscencia cartesiana, la cuestión relevante es si el yo existe o, por el contrario, como la vida, parafraseando los versos calderonianos de La vida es sueño, se trata de una ilusión, una sombra, una ficción. Junto a los estudios anatómicos del cerebro hay otra línea de investigación sobre el mismo para tratar la cuestión del yo, el análisis de aquellos sujetos que padecen trastornos mentales y que presentan un funcionamiento parcial o alterado. De estas investigaciones parece colegirse que no hay un solo yo, sino muchos estados diferentes del yo (yo-cuerpo, yo-localización, yoperspectivista, yo como sujeto vivencial, yo de autoría y control, yo-autobiográfico, yo-autorreflexivo...). Cada uno de esos estados del yo puede sufrir trastornos funcionales y, con la ayuda de las neuroimágenes, pueden advertirse tales funcionamientos alterados según las distintas regiones cerebrales. En realidad, todos estos estados del yo que, teóricamente, pueden distinguirse con cierto nivel de precisión, en el funcionamiento real del cerebro forman un complejo entramado sistémico que, para muchos neurólogos, consiste en un "flujo de sensaciones del yo", y que tal vez podríamos denominar simplificadamente yo, estableciendo la existencia del yo después de constatar que nos sentimos como un yo, imperfecto y contingente, pero, en cierto modo, como Bauman afirma, con la posibilidad de actuar conscientemente, "aun sin la comodidad de la certeza del éxito" (2007a, 224). La hipótesis de que somos un conjunto de sensaciones que navegan solas por el mundo no parece definitiva ni acaso verosímil. 
Al carácter fluido y situado de los procesos configuradores de nuestra identidad, a ese "yo distribuido" que diría Bruner (1991), hay que unir la naturaleza narrativa como rasgo esencial de la identidad personal. Como afirma este autor, el yo puede considerarse un "suceso verbalizado", un tipo de "metasuceso" que aporta coherencia y continuidad a la experiencia, que adquiere significado en las circunstancias históricas de la cultura en la que participa y se mantiene en unos significados, lenguajes y narraciones cultural e históricamente específicos. No es el lenguaje por sí mismo, sino la narrativa lo que está en la base de la identidad personal, posibilitando la construcción del yo, y suponiendo un equilibrio entre la autonomía personal y el compromiso con los otros. La narrativa, así, es el medio a través del que se crea y recrea el sentido del yo. No se trata, por tanto, de que el yo sea una emergencia desde las profundidades de la subjetividad, sino más bien el producto de nuestra narratividad. Acaso sin nuestra capacidad de construir historias sobre nosotros mismos no existiría algo como el sentido del yo.

De esta forma, la memoria autobiográfica sería una construcción del yo y cumpliría funciones tanto individuales como sociales, cifradas en el establecimiento de un sentido del yo y en la situación del individuo en el contexto cultural de pertenencia. La construcción con sentido de la identidad personal puede reunirse en un concepto sistémico de la persona, que refleja su fragilidad y levedad, su ámbito para la experimentación y la diferencia, pero también su construcción en relación dialéctica con el otro, con los demás, en contextos culturales específicos. El yo no es algo previo a lo social, "sino el producto de la interacción con los otros que ha tenido lugar desde nuestros primeros años" (Appiah, 2007, 51). Como señala Taylor (1997), reconozcamos a la agencia humana toda la gloria que le corresponde, pero no olvidemos que es algo constituido por el entramado de prácticas y colectividades de las cuales emerge y a las que pertenece.

Tomar decisiones acerca del curso que se desea dar a la propia vida es autodeterminarse. Obviamente, aunque la autonomía puede considerarse principio supremo de moralidad, comprende muchos otros ámbitos de la vida humana (político, profesional, de ocio, etc.). La posibilidad de esta autonomía en los distintos ámbitos vitales es una condición de la felicidad posible de cada persona y un requisito imprescindible para la participación en la vida cívica. Si cabe hablar del deber ético de hacer cada uno su vida, éste está, como dice Appiah (2007), inevitablemente unido a los aspectos éticos de la vida de los demás, puesto que estamos involucrados en un proyecto social y político compartido. Aquí se manifiestan nuestros márgenes de autonomía y responsabilidad. La libertad de pensamiento y acción, necesaria para el descubrimiento de la realidad y para el desarrollo de la existencia auténticamente humana, es precursora del ideal más expansivo de la libertad política o civil.

Tal vez el equilibrio social no esté tanto en peligro por el avance de un conocimiento científico, probablemente cimiento y pretexto para una progresiva exculpación de los individuos, sino por el desgaste de los beneficios que proporciona asumir la responsabilidad individual. Cuando se limita la dominación hasta permitir 
que cada sujeto decida por sí mismo y se implique en las decisiones colectivas, es decir, cuando se da una situación de "libertad positiva", por recordar la célebre distinción conceptual de Isaiah Berlin (2004), nos encontramos en el ámbito de la autonomía. Pero poder conducirse autónomamente no significa necesariamente querer y saber hacerlo (la libertad se nos ofrece como condición necesaria pero no suficiente), sino, especialmente, tener la voluntad de querer serlo y la capacidad para lograrlo, por lo que la relevancia de la educación en este quehacer parece obvia. Hay que proporcionar recursos y valor para ser autónomos en un marco caracterizado por la incertidumbre y la contingencia. Al tiempo, esta educación de la autonomía ha de fundamentarse en una educación de la responsabilidad.

\section{LA AUTONOMía Y LA IDEA DE SER SUJETO DE DERECHOS}

Una de las dimensiones fundamentales en el estudio de la autonomía proviene de su vinculación histórica y antropológica ${ }^{1}$ con el reconocimiento paulatino de derechos. Este proceso es una de las causas del surgimiento y valoración de la idea de la autonomía y la emancipación de los sujetos (Schneewind, 2010). De hecho, si bien el reconocimiento de derechos tiene en una de sus primeras expresiones salvaguardar la libertad religiosa y, por tanto, la libertad de credo, esto ha de interpretarse dentro de un marco más amplio en el que se considera fundamental para el ser humano reconocerle espacios de autonomía, independientes del Estado, que salvaguarden el ejercicio libre, sin peligro sobre su propia vida y la de los suyos, de sus convicciones y expectativas acerca de los fines deseables de la vida (Peces-Barba, 1987). El avance de las diferentes generaciones de derechos fundamentales del ser humano -ya se hace referencia a la cuarta generación-, puede interpretarse como un proceso de amplitud de la perspectiva de la autonomía del sujeto y, en concreto, de la necesidad de salvaguardar sus posibilidades de acción y, en su caso, de omisión del ejercicio de esa autonomía. No cabe duda de que si hay algo de lo que podemos estar humanamente orgullosos -sin olvidarnos de lo que queda por lograr- es precisamente del afianzamiento y extensión de los derechos como ámbito de protección, a la vez que de la consecuente exigencia de responsabilidades.

\subsection{La persona, sujeto de derechos}

Lo que nos interesa destacar, en este momento, es que no nos estamos refiriendo sólo al hecho del número de derechos, o la categoría de derechos, a los

1. Nos referimos a una antropología filosófica clásica que no olvida, pero ahora no considera, las interesantes y necesarias reflexiones que se han hecho en nuestro ámbito sobre las implicaciones biológicas de la autopoiesis (García Carrasco, 2007; García del Dujo, García Carrasco y Asensio, 2006). 
que un sujeto tiene acceso en un país determinado o en una zona política y geográfica concreta. Estamos acentuando la idea de que se ha extendido y se sigue extendiendo la conceptualización teórica y práctica de la idea de persona, de ser humano, estrechamente vinculada a la percepción de la misma como sujeto-dederechos. Es decir, hoy por hoy no cabe entender al ser humano sin, al mismo tiempo, pensarlo como alguien cuyo desarrollo está sometido al reconocimiento de derechos. Ser persona es ser sujeto de derechos.

Correspondiente al sujeto desvinculado y libre, está la visión de una sociedad hecha del consentimiento de individuos libres y por dicho consentimiento y, en consecuencia, la noción de una sociedad constituida por portadores de derechos individuales. Ésta, quizás, es una de las imágenes de la sociedad más profundamente arraigada de las que haya arrojado la civilización moderna (Taylor, 1996, 157).

Es interesante observar el importante matiz de que esta vinculación es más una referencia moral que jurídico-positiva. Se es más persona si se tienen más derechos. Se tiene más capacidad de autonomía si se tienen más derechos. Y, por último, entonces, se es más persona si se es más autónomo. Este nexo de unión es el que explica la creciente extensión de la demanda de derechos por todo tipo de sujetos, individualmente considerados, y en las más diversas circunstancias imaginadas, o mejor por ellas; y, del mismo modo, por todo tipo de colectivos, o para todo tipo de cosas o seres vivos no humanos. En suma, tener derechos es un horizonte valorativo en sí mismo, autotélico e ilimitado.

Otra idea que nos interesa destacar para entender el alcance educativo de la vinculación entre derechos y autonomía es la referida a las posibilidades de acción. En cuanto se inicia una lucha para modificar, transformar o revolucionar un estado de cosas dado y se proponen unos nuevos derechos o se denuncia la ausencia de los mismos, el enemigo está identificado y delimitado, en cualquier caso, se barrunta algo que se desea modificar o crear. Es así como han ido surgiendo las diferentes declaraciones y generaciones de derechos. Es así también como se han iniciado los grandes cambios sociales y las revoluciones de los diferentes países y culturas. La perspectiva, sin embargo, cambia cuando la reivindicación de derechos carece de una causa concreta por la que luchar, perfectamente delimitada. La reivindicación de derechos puede ser interpretada, entonces, como una expectativa de apertura total a la realidad, como posibilidades de ser, estar y hacer en esa realidad. Tener más derechos es lo que te permite ser más persona porque el ser personal se constituye desde la perspectiva de la autonomía, esto es, desde las posibilidades de acción que abren esos derechos: cuantas más posibilidades -derechos- tienes, mejor eres y mejor puedes ser. Al comprender la autonomía como apertura total a la realidad se tiende a valorar, en sí misma, la pluralidad personal y social de acciones, las vivencias de experiencias, de acontecimientos, de situaciones, etc. $\mathrm{Y}$ esto, si bien puede tener sus naturales inconvenientes, alarmas o riesgos desde un punto de vista educativo y ético, es, sin lugar a dudas, muy positivo para el desarrollo humano. 
Hablar de derechos universales, naturales o humanos es vincular el respeto hacia la vida y la integridad humanas con la noción de autonomía. Es considerar a las personas cooperantes activos en el establecimiento e implementación del respeto que les es debido. Y ello expresa un rasgo esencial de la perspectiva moral occidental moderna. Ese cambio de forma, naturalmente, va paralelo a otro de contenido, el del concepto de lo que significa respetar a alguien. Ahora se hace crucial la autonomía y, por tanto, en la trinidad lockeana de los derechos naturales se incluye el derecho a la libertad. Y para nosotros el hecho de respetar la personalidad implica, esencialmente, respetar la autonomía moral de la persona (Taylor, 1996, 31).

\subsection{La autonomía y el reconocimiento del individuo como sujeto de derechos}

Para poder entender el nexo que anunciamos al principio entre autonomía y derechos es necesario volver a retomar la identidad. No se trata sólo de que el sujeto gane en autonomía por la realización de acciones o, como se ha dicho, que debido a la idea de acción, o más exactamente, a la constitución de la idea de agente en términos de acción se llega a la idea de autonomía, se trata también de que la propia acción, como sujeto autónomo, genera una identidad. Vincular los términos de acción y de autonomía con el de identidad abre a su vez otras interpretaciones epistemológicas e incluso ontológicas. A través de la realización de acciones el sujeto adquiere su propia identidad. No somos nada hasta que hacemos algo. Somos lo que hacemos. Las acciones no son sólo posibilidades de realización sino de definición, de lo que constituye, define y hace al sujeto. Ésta es una de las consecuencias trágicas de nuestra situación de postkantianos: "La identidad del sujeto no es la que corresponde a una realidad cerrada y sustante, otorgada previamente como un dato de partida irrebasable (yo = sustancia), sino una identidad que descansa más bien en los resultados de su propia actividad" (Arenas, 2002, 472; Derrida, 1994). Llegamos así, desde esta perspectiva, a la idea del sujeto construido, de la identidad humana como producto de una construcción. El sujeto es resultado de su propia actividad autónoma y autofundante.

La referencia que hacíamos a los derechos podrá verse ahora con mayor nitidez y entender así mejor el círculo interpretativo que sugerimos al principio. La autonomía, decíamos, se percibe desde el reconocimiento del individuo como sujeto de derechos. Se es más autónomo si se tienen más derechos, esto es, más posibilidades de acción. Pues bien, la perspectiva de la identidad aporta la base ontológica a todo este proceso en la medida que las posibilidades de acción son, como acabamos de mostrar, posibilidades de ser. La apertura total a la realidad en la que, según vimos, se entiende la autonomía y la condición de ser sujeto de derechos puede verse ahora también, además, como apertura total a la identidad, a las identidades. La acción pertenece y define la identidad o identidades del sujeto. Los sujetos reivindican así derechos para reivindicar su autonomía, para reivindicar la posibilidad de realización de acciones y, por lo que acabamos de añadir, para reivindicar identidades, formas plurales de ser, estar y hacer. 
Esta perspectiva antropológica según la cual el sujeto no solamente es agente de sus propias acciones, sino que, a través de éstas, va adquiriendo o asentando una condición humana o una naturaleza humana, ha tenido y sigue teniendo especial relevancia en el campo pedagógico. No hace falta remitirnos aquí a las implicaciones y extensiones del constructivismo, de la construcción de valores, de los diferentes enfoques de la ciudadanía, de la educación moral e incluso de ciertas perspectivas de la educabilidad que se sostienen desde la concepción de un sujeto sin una naturaleza humana estable.

Un freno, estrictamente lógico a este enfoque, es el razonamiento según el cual, siguiendo a Millán Puelles, para poder decir que algo se ha construido, modificado o realizado, ese algo tiene, como principio operativo, que permanecer. «Sólo algo que permanece se puede transformar" $(1967,310)$. Desde esta perspectiva la naturaleza humana no es, precisamente, la que impide los cambios sino la que los posibilita, la que los hace posibles.

Ahora, la cuestión clave entonces con respecto a la autonomía estriba en clarificar ¿̇de dónde surge el yo que-es-autónomo? Y mejor ya, desde una perspectiva pedagógica, ¿a dónde decimos a nuestros educandos que miren para ser más ellos mismos, para ser más autónomos, para ser más auténticos?

La relación que hemos mostrado de la autonomía con respecto a los derechos, las posibilidades de acción y la identidad tiene como consecuencia principal que "todo el mundo tiene derecho a desarrollar su propia forma de vida, fundada en un sentido propio de lo que realmente tiene importancia o tiene valor. Se les pide a las personas que sean fieles a sí mismas y busquen su autorrealización. En qué consiste esto debe, en última instancia, determinarlo cada uno para sí mismo. Ninguna otra persona puede tratar de dictar su contenido" (Taylor, 1994, 49-50). Esto es, en sí mismo, una conquista moral extraordinaria. Un éxito de las intuiciones del desarrollo humano y una vigorosa propuesta que, por un lado, revaloriza, como nunca había ocurrido antes, a la misma educación, pero, por otro, la sitúa en una posición de cierta arrogancia y riesgo: ¿cabe enseñar modos más valiosos de ser fiel a uno mismo, de ser más auténtico, más autorrealizado?

\subsection{El limite de los derechos como marco de referencia de la autonomía}

Si bien la autonomía se constituye, según hemos visto, desde el reconocimiento de derechos y, especialmente, desde la percepción de los individuos como sujetos de derechos, el marco de referencia de la autonomía no es, sin embargo, el propio derecho, ni cualquiera de los conjuntos de derechos que podamos imaginar. Somos gracias a los derechos, pero la autonomía, en su radicalidad, no se entiende sólo desde la consideración de la persona como sujeto de derechos. Más aún, y nos evitaríamos muchos errores políticos y sociales si se valorase acertadamente, que es gracias a la autonomía de los sujetos por lo que puede mantenerse y mejorar el orbe de derechos. 
Hay una preeminencia moral de la autonomía del sujeto frente a todo tipo de derecho, grupo o sociedad, porque es ese mismo sujeto el único capaz de divisar intuiciones acerca de situaciones, que, dadas por justas o convenientes, sin embargo, no lo son. Es el sujeto, su autonomía, la que nos puede enseñar a ver la realidad de otro modo. Nos resulta especialmente importante acentuar esa revalorización de la autonomía de los sujetos porque son esos mismos individuos los que tienen que enfrentarse, con demasiada frecuencia, a las instituciones vigentes, a los valores dominantes, a las costumbres imperantes, para hacernos ver otra forma de interpretar la realidad, no presente y reconocida en las instituciones, valores y costumbres dominantes. Son esos sujetos $-\mathrm{y}$ no el derecho- quienes intuyen desde sus propias convicciones -éticas o religiosas- otras posibilidades del desarrollo humanizador y de la convivencia humana.

De este modo, acertamos a establecer las condiciones adecuadas para favorecer el progreso cuando no sólo salvaguardamos un estado jurídico determinado, sino cuando, más especialmente, protegemos, desde ese mismo orden jurídico, el valor proyectivo y creador de la autonomía de los sujetos. Al defender la autonomía defendemos en rigor las posibilidades de transformación de los significados y las prácticas reales de los sujetos consigo mismos, con los demás y con la realidad que les ha tocado vivir (Gil Cantero, 2008).

Esta perspectiva de la autonomía no supone, con respecto a una posición comunitarista, un desligamiento o distanciamiento. Tampoco supone, con respecto a un enfoque universalista, un mero contrapeso egocentrista o individualista. Todo lo contrario: tanto el universalismo como el comunitarismo requieren una perspectiva del sujeto como persona autónoma en la consideración de sus aspiraciones más ideales y utópicas.

Es el sujeto quien, en el ejercicio de su autonomía, desde su vida particular o pequeña comunidad establece las condiciones que hacen posible la universalización de las verdades de la razón. Y es ese mismo sujeto autónomo quien, desde sus visiones más universales, más ideales y utópicas, hace posible la concreción particular de las verdades prácticas en su vida y en sus pequeñas comunidades.

En las posibilidades de la autonomía del sujeto está lo concreto y lo universal. En las posibilidades de la autonomía del sujeto es donde podemos cumplir el criterio del cambio individual y social: no identificar en un estado de cosas dado por muy dominante, apoyado y extendido que esté (sean leyes, contenidos curriculares, fines educativos o costumbres de ocio) la verdad cerrada y única de las posibilidades de desarrollo humano. En las posibilidades de la autonomía del sujeto encontramos que ningún debate ético queda cerrado. En las posibilidades de la autonomía del sujeto encontramos la fuerza creativa e indomable, las intuiciones rompedoras e inesperadas que nos muestran las expectativas, siempre abiertas, de lo posible y de lo mejor del ser humano.

En efecto, el derecho a desarrollar la autonomía significa, por un lado, el derecho a desarrollar libremente nuestro propio proyecto personal de vida sin que 
nadie ni nada pueda realizarlo por nosotros y, al mismo tiempo, se abre el horizonte de responsabilidades, al comprender que el derecho a la autonomía incluye también el deber de caracterizar humanamente ese proyecto sin que nadie ni nada pueda humanizarlo por nosotros.

La libertad, pues, en el desarrollo y logro de la autonomía incluye evitar tanto la suplantación o sustitución de nuestro propio proyecto personal de vida como de las responsabilidades humanizadoras del mismo. Esto es especialmente interesante porque indica que la responsabilidad no es una condición sobrevenida sino que se encuentra inserta en la propia condición constitutiva del logro de la autonomía.

De este modo, la adopción de responsabilidades es lo que permite que la autonomía se inserte dentro de un contexto valorativo, ya que "únicamente desde premisas valorativas el proceso de autocontrol puede ser un proceso de optimización" (Capafons et al., 1985, 58). Se trata de provocar la tensión necesaria por desarrollar un proyecto personal de vida, por saberlo defender, mantener y, sobre todo, por contrastar con otros proyectos personales de vida de otros sujetos y grupos (Bárcena y Mèlich, 1999). La referencia, en el contexto pedagógico, a los contextos valorativos o, en general, a la presencia de los valores, en el modo en que se desarrolla la autonomía, tiene especial importancia porque permite destacar ciertas peculiaridades de interés educativo. En efecto, por lo que estamos defendiendo aquí la autonomía implica la participación activa, personal y comprometida en el conjunto de valores que se considere que merece la pena vivirse por favorecer los proyectos deseables de felicidad. La autonomía, por tanto, no acentúa necesariamente la originalidad, el individualismo y el solipsismo, sino la participación activa y personal, el desarrollo de un estilo propio, el sentir particularizado de esos valores y la proyección personal de los mismos. La participación activa y personal en unos valores ya establecidos no anula ni cuestiona la autonomía de los sujetos.

Una educación basada en ayudar al sujeto a situarse, a situar su autonomía, desde la percepción de ser agente de posibilidades de acción. La educación que aspira a formar sujetos autónomos lo primero que transmite a los educandos es que la expectativa de alcanzar la autonomía estriba en la adopción de un particular proyecto de situación y relación comprometida con el mundo. Que esa elección tiene que hacerse propia, que nadie, como vimos, puede sustituirles y que la revalorización de esa situación y de esa relación de compromiso que inaugura su elección es responsabilidad suya que se mantenga y crezca desde criterios de valor contrastados y exigentes. Soy autónomo porque elijo libremente qué situación y relación de dependencia con el mundo voy a cuidar, hacer crecer y desarrollar. "El reconocimiento de la dependencia es la clave de la independencia" (Macintyre, 2001, 103), es decir, la dependencia es lo que convierte, precisamente, a los seres humanos en autónomos y responsables. 


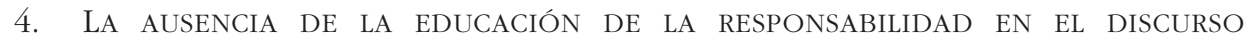
PEDAGÓGICO

Si se considera este discurso como el conjunto de teorías que, con pretensión científica o con pretensión de racionalidad práctica, se han venido elaborando en la segunda mitad del siglo xx para la interpretación de los hechos educativos o para la orientación técnica de las acciones educativas, el tema de la responsabilidad no ha tenido una presencia suficiente en la elaboración teórica y en la práctica de la educación.

No hay duda de que el debate sobre la educación en la responsabilidad obliga a considerar todos los escenarios educativos posibles. Máxime si aceptamos que las personas construyen su identidad a partir de las experiencias generadas en los múltiples contextos en los que viven y que el fin último de la educación es el pleno desarrollo de la personalidad de cada sujeto. En este sentido, ninguna acción educativa puede ser independiente de las otras, puesto que los sujetos construyen su identidad personal a partir de todas las experiencias que reciben y que dejan huella en ellos y tal construcción no se realiza en compartimentos estancos. Un criterio razonable consiste en identificar los contenidos formativos de cada una de las agencias de la educación y las consecuentes responsabilidades únicas y/o compartidas que tienen, que conlleva exigirles su deber de desarrollo de las capacidades de todo individuo como miembro de la especie humana (Cortina, 2009), ya que éstas únicamente podrán desenvolverse desde la especie humana y en comunidades humanas. Por ello, nos vamos a ocupar de las condiciones necesarias para la autonomía y la responsabilidad centrándonos en los sujetos y no tanto en las condiciones particulares de los escenarios donde sucede la educación. En los apartados que siguen afrontaremos esta tarea partiendo del derecho a la educación tal y como se reconoce en el artículo 26 de la Declaración de Derechos del Hombre y en el artículo 27 de la Constitución española ${ }^{2}$.

\subsection{Toda persona tiene derecho a la educación}

El desarrollo del ser humano está en función de dos grupos de factores: los factores de la herencia y de la adaptación biológica, y los factores de la transmisión o de interacción social. Hablar del derecho a la educación es, en primer lugar, constatar el papel indispensable de los factores sociales para la formación del sujeto. La diferencia esencial entre las personas y los animales reside en que las principales características humanas no vienen determinadas por mecanismos hereditarios, sino que se adquieren por transmisión exterior, de generación en

2. Los siguientes apartados siguen el esquema del artículo de PIAGET, "Le droit à l'éducation dans le monde moderne" (1948), que redactó a instancias de la UNESCO, una joya sobre las capacidades específicamente humanas. 
generación, es decir, por la educación, y sólo se desarrollan en función de interacciones sociales múltiples y diferenciadas. Es cierto que el sistema nervioso permite la adquisición de tales características humanas, pero sólo se hacen efectivas por una transmisión social exterior, principalmente educativa.

Si las capacidades lógicas se construyen en la interacción social en lugar de ser innatas, la primera tarea de la educación consiste en formar la razón. La proposición "toda persona tiene derecho a la educación" como afirma solemnemente el inicio del artículo 26 significa, en primer lugar, que todo ser humano tiene derecho a estar en un contexto escolar en el que pueda elaborar, hasta su acabamiento o plenitud, en interacción con compañeros y profesores, esos instrumentos indispensables de adaptación que son las capacidades intelectuales para las operaciones de la lógica.

Lo que se afirma de los instrumentos de la razón es más evidente respecto a la formación moral. Es verdad que ciertas disposiciones innatas permiten al ser humano la construcción de normas y sentimientos morales, pero su implementación efectiva supone un conjunto de relaciones sociales tanto en la familia como en contextos sociales más amplios. El derecho a la educación moral supone, como el derecho a la formación de la razón, el derecho a construir realmente, o al menos a participar, en la elaboración de las normas a cuyo mandato hay que obedecer. La educación moral es un problema de autogobierno, paralelo a la autoformación de la razón, en el seno de una comunidad humana.

Conviene insistir en que el derecho a la educación intelectual y moral implica, más que un derecho a adquirir conocimientos, el saber forjar ciertos instrumentos preciosos del espíritu entre todos los que interactúan en un medio social. La educación así entendida es una condición formadora y necesaria del desarrollo natural mismo. Es garantizar a todo individuo el entero desarrollo de sus funciones mentales, así como de los valores morales correspondientes al ejercicio de esas funciones hasta su adaptación a la vida social actual. El derecho a la educación es pues, ni más ni menos, que el derecho del sujeto a desarrollarse humanamente, en función de las posibilidades de que él dispone, y la obligación o deber de la sociedad de convertir esas posibilidades en realizaciones efectivas y útiles.

\subsection{La educación tendrá por objeto el pleno desarrollo de la personalidad bumana}

La promoción del "pleno desarrollo de la personalidad humana" significa la formación de personas capaces de autonomía personal, intelectual y moral, a la vez que respetuosas con la autonomía de los otros en virtud precisamente de la regla de reciprocidad que la hace legítima para ellos mismos.

El pleno desarrollo de la personalidad es indisociable del conjunto de relaciones afectivas, sociales y morales que conforman todo escenario, incluida la escuela. En realidad, la educación forma un todo indisociable y no es posible formar personalidades autónomas en el dominio moral si los individuos son 
sometidos a la imposición intelectual de unos conocimientos que les impulsa a aprender sin descubrirlos por ellos mismos. Si el alumno es pasivo intelectualmente, no será libre moralmente y, viceversa, si es pasivo moralmente no desarrollará un pensamiento curioso que busque el descubrimiento de nuevos conocimientos.

Los derechos surgen cuando una sociedad está dispuesta a reconocer que algunas capacidades de las personas son indispensables para llevar una vida digna y que, por tanto, tienen derecho a exigir la protección de su desarrollo. Esas capacidades tienen que ser percibidas como valiosas por la sociedad y ésta tiene que tener alguna razón para sentirse obligada a ayudar a los sujetos a su desarrollo (Cortina, 2009). Y esto es lo que sucede en la sociedad española cuando reconoce, en el artículo 27 de la Constitución, el derecho de los ciudadanos a la educación, gratuita y obligatoria, hasta el pleno desarrollo de su personalidad. En otras palabras, desarrollar prioritariamente las capacidades intelectuales y morales que posibilitan a los sujetos ser libres y responsables.

\subsection{La responsabilidad por uno mismo}

La autonomía o señorío sobre uno mismo se consigue cuando se tienen pensamientos propios, aquellos de los que se puede dar cuenta y no pensamientos impuestos. También cuando se toman las decisiones que le afectan a uno según los proyectos de su vida personal, porque considera que son las mejores para él, y tales decisiones no son tomadas por otras personas según otros intereses o proyectos, aunque sean bienintencionados. La responsabilidad consiste, en una primera aproximación, en la asunción de la propia autonomía, es decir, en la aceptación de que soy capaz de alcanzar pensamientos que puedo justificar y tomar decisiones de las que puedo dar cuenta a los demás y a mí mismo (Escámez y Gil Martínez, 2001; Escámez, 2008).

La responsabilidad por uno mismo consiste en echarnos nuestra vida a la espalda y decidir qué camino tomamos y a dónde nos dirigimos. Realmente no sabemos si tendremos éxito en el camino emprendido, ya que cualquier decisión que tomemos puede estar equivocada, pero, al menos, nuestro comportamiento estará a la altura de la dignidad humana puesto que seremos guionistas y actores del proyecto de nuestra vida.

\subsection{La responsabilidad por el otro}

La interiorización de la relación de responsabilidad para con los otros, aun con los desconocidos, significa descubrir que vivir no es un asunto privado, sino que tiene repercusiones inevitables siempre que vivamos en sociedad. Máxime si es una sociedad muy heterogénea con múltiples opciones en las formas de pensar y vivir. Ello implica tener que aprender a convivir con otras personas de diferentes ideologías, creencias y estilos de vida. Y vivir "Con" los otros genera 
una responsabilidad. O lo que es lo mismo, nadie me es ajeno ni extraño, nadie me puede ser indiferente, y menos el que está junto a mí. El "otro" forma parte de mí como pregunta y como respuesta (Ortega, 2010). Frente al otro he adquirido una responsabilidad de la que no me puedo desprender, de la que debo dar cuenta. El otro, cualquier otro, siempre está presente como parte afectada por mi conducta sin más argumento que el de su vulnerabilidad. No puedo abdicar de mi responsabilidad hacia él, porque siempre "el rostro del otro me concierne" (Lévinas, 2001, 181).

El encuentro con el otro es ante todo mi responsabilidad respecto de él. Pero yo no vivo en un mundo en donde sólo hay un cualquier hombre; en el mundo siempre hay un tercero: que es mi otro, mi prójimo (Lévinas, 2001). Al otro y al yo les une una relación profunda de deferencia, de responsabilidad, es decir, ética.

Este enfoque conlleva la deconstrucción del sujeto moderno y la construcción de una identidad moral que no se define como la relación del yo consigo mismo, sino como la relación con el otro, como respuesta al otro y del otro interpelante, hasta el punto de llegar a una descentración radical del punto de vista de mis derechos o de nuestros derechos y su sustitución por los derechos de los otros. En esta ética el sujeto sólo llega a ser sujeto moral en la medida en la que su identidad se transforma, se quiebra por la presencia del otro. En este acto de descentramiento del propio yo, el sujeto se hace responsable del otro, es decir, sujeto moral (Ortega, 2010). Éste es el fundamento ético de las teorías educativas del cuidado y de los currícula que proponen.

\subsection{La responsabilidad por la ciudadanía política}

Pero hacerse cargo del otro implica asumir la realidad del contexto sociohistórico en el que vive. Por ello, la responsabilidad ética por el otro es inseparable de la acción política. No es posible construir una sociedad para todos sin la participación de todos, desde la convicción y creencia de que los asuntos públicos nos/me atañen, nos/me afectan, y de ellos también somos/soy responsables. Es decir, una democracia sólo puede funcionar si la mayoría de sus miembros están convencidos de que su comunidad política es una empresa común en la que la participación de todos y cada uno es la única garantía de su pervivencia (Escámez, 2003).

Sin la conciencia de que la construcción de la sociedad democrática es una tarea que no puede delegarse, las propuestas de participación ciudadana resultan ineficaces. Sin ciudadanos no hay ciudadanía, es decir, vida democrática. Es necesario, por tanto, ir más allá de la persona informada, procurando personas que no sólo tomen conciencia crítica de las situaciones injustas, de las dinámicas sociales, económicas y políticas que las generan, de lo que está pasando, sino que son necesarias personas que desarrollen estrategias que les permitan reaccionar ante aquellas situaciones no como víctimas ni dependiendo de otros, sino como ciudadanos activos, con capacidad para dar respuesta a sus propios problemas y a los problemas de sus comunidades políticas. Al desarrollo de los sujetos como ciudadanos libres, interdependientes, críticos con las situaciones sociales injustas 
y activos políticamente, podemos colaborar educando para "la resistencia y la resiliencia en las sociedades marcadas por la incertidumbre y el riesgo" (Novo, 2007, 359).

\subsection{El desarrollo de la identidad moral: de la responsabilidad personal a la responsabilidad social}

Ciertamente el sujeto es quien elige de un modo original y peculiar y, en ese sentido, tendrá una auténtica identidad moral. Pero también es cierto que la elección del sujeto no se produce en el vacío, ni es fruto del puro capricho, sino que el sujeto elige en el horizonte de cosas, situaciones o acontecimientos que tienen valor, que valen la pena, que tienen importancia. Dicho de otro modo, sólo se puede definir la identidad moral con el trasfondo de aquellas cosas que tienen importancia, es decir, el yo se va construyendo a partir de las exigencias de la naturaleza, de mi respuesta a las necesidades del otro o a los deberes con los míos (Taylor, 1994). Poner entre paréntesis a la naturaleza, la sociedad, la solidaridad con la familia, todo salvo lo que encuentro en mí, significa eliminar a todos los candidatos que pugnan por lo que tiene importancia.

El desarrollo de la identidad moral hay que entenderlo como lo que empuja a autogobernarse, a aprender a cuidar de uno mismo, a ocuparse del mundo para hacerlo un lugar habitable y a acoger al otro (Bárcena, 2003). Ciertamente que la identidad moral significa que el sujeto decide y actúa de acuerdo a su conciencia, superando las presiones o dificultades que le impongan desde fuera o superando las dificultades y obstáculos que puede encontrar en la fuerza de sus pasiones o en la debilidad de su voluntad. La identidad moral significa, por tanto, que el sujeto se responsabiliza del ajuste de los actos que vaya realizando a las exigencias de lo que ha elegido en conciencia como norma o criterio de su deber.

La apelación a la conciencia personal no es apelar a una interioridad desconectada del medio ambiente, de las relaciones interpersonales y sociales. El compromiso, además de con uno mismo, le vincula con los demás, puesto que con ellos convive y a ellos afectan las consecuencias de sus actos u omisiones. La implicación y el compromiso personal con los demás y con el medio ambiente son centrales en la ética, puesto que el sujeto humano sin el otro, sin las relaciones que le vinculan al otro, no se entiende como sujeto moral. Es la dependencia que le ata al otro u otros, la necesidad de responder a los demás y de los demás la que le libera de su ensimismamiento y le otorga la dimensión moral (Ortega, Touriñán y Escámez, 2007).

Ahora, si nos situamos desde la perspectiva de las organizaciones, ésta no es simplemente un agregado de individuos, por lo que tiene una estructura que le lleva a funcionar de forma organizada, entonces debe estar dotada de rasgos análogos a los que hemos reconocido como propios de un organismo humano. Esto significa que debe tomar conciencia de qué valores y metas deben orientar sus decisiones, porque son los que le ayudarán a ir conformando una identidad, 
un carácter propio de la organización. Y también que la organización, como tal, debe hacerse responsable de sus decisiones y de las consecuencias previsibles que de ellas se siguen (Cortina, 1998). Es indudable que, en último término, las organizaciones se componen de personas, pero también lo es que en ellas existe un procedimiento aceptado, más o menos de modo explícito, a través del cual se toman las decisiones, de suerte que el responsable de las decisiones no es cada uno de los miembros de la organización, sino la organización en su conjunto. A esto es a lo que se denomina responsabilidad social.

Así una institución asume su responsabilidad para con la sociedad, resolviendo o contribuyendo a la resolución de los problemas de la comunidad, y para con los individuos que forman parte de ella, atendiendo sus derechos y su desarrollo personal. En definitiva, es una forma de autorregulación, que se caracteriza por su carácter voluntario, y la formulación de acciones efectivas para la mejora social, laboral, medioambiental y de respeto a los derechos humanos. En este sentido, la responsabilidad de las instituciones educativas hacia la sociedad y su necesaria implicación en la resolución de los problemas sociales es en estos momentos incuestionable. De este modo, cada institución, y de modo incuestionable las educativas, debe ser conciente de su responsabilidad en los impactos de las medidas y acciones emprendidas; ante la lógica complejidad de la realidad, reclama una visión y un enfoque sistémico de sus actuaciones; sostiene la autorregulación dirigida a la capacidad de servir a los intereses y necesidades de todos los actores, corrigendo los errores, y asegurado la sostenibilidad y el equilibrio de esa institución (Díaz de Iparraguirre, 2008).

\section{HACIA UNA REVALORIZACIÓN DE LA INSTITUCIÓN EDUCATIVA: SU RESPONSABILIDAD COMO ÁMBITO DE CONSTRUCCIÓN DEL SUJETO}

Nadie cuestiona que la emergencia de los fenómenos de subjetivación, de construcción del sujeto, implica un sólido alegato de los derechos personales sobre todas las maneras posibles de integración social. Ninguna persona debe renunciar a su derecho a ser ella misma, o sea, a su capacidad de autonomía. Ahora bien, la educación tiene el deber de formar a cada sujeto para que sea capaz de vivir conforme a la imagen de sí mismo, de acuerdo a su autonomía y responsabilidad, en un mundo donde múltiples miradas son posibles. Esta nueva mirada social supone que la unidad de los comportamientos humanos no venga impuesta por ninguna cultura determinada ni por la especificidad de alguna sociedad determinada, sino por la construcción personal de cada sujeto, siendo al mismo tiempo un ser singular, único, y portador de derechos universales (Touraine, 2009). Junto con el reconocimiento de la pluralidad de nuestras identidades y sus distintas implicaciones, hay una crucial necesidad de apreciar el papel de la "elección" al determinar la importancia de identidades particulares que son inevitablemente diferentes (Sen, 2007).

Las instituciones deben cuidar a los individuos y a las colectividades en cuanto sujetos de derechos, de modo que, si éstos son amenazados, dichas instituciones 
deberían ser reformadas. Los nuevos actores ya no quedan definidos simplemente como "Sociales", es decir, dentro de los márgenes de las normas y de los mecanismos sociales, sino más bien con su construcción como personas. Como ha puesto de relieve Anthony Giddens (1997), hemos ido adquiriendo progresivamente mayor protagonismo en la conducción de nuestras vidas. Las nuevas formas de identificación de los individuos (reflexivas, narrativas...) no están aún completamente reconocidas ni enteramente constituidas (Dubar, 2002), pero hemos de prestar toda la atención a lo que pensamos y hacemos para darnos cuenta de las nuevas categorías que ya están organizando nuestras vidas. En todos estos fenómenos de construcción identitaria hay un componente "individualista", ya que se propugna la autoafirmación, el derecho a establecer la propia crónica del yo, el derecho de toda persona a establecer sus derechos; pero también se da un componente "universalista", puesto que todos los derechos del hombre deben ser defendidos en todos los frentes y en cualquier parte de nuestro mundo.

Las propuestas pedagógicas para la autonomía y la responsabilidad han de partir de las nuevas realidades socioculturales, si no queremos caer en la extemporaneidad. Emerge quizás con más fuerza que nunca la necesidad de considerar la educación como elaboración de sentido personal en la cultura. Se trata, como ha afirmado Bruner (2000), de crear un mundo que dé sentido a la vida, a los actos humanos, a las relaciones humanas. El hallazgo de este sentido personal se da en una profunda reciprocidad con el sentido social o compartido, uno fortalece al otro y se debilitan en ausencia del otro. Desde una perspectiva pedagógica, hay una cuestión especialmente preocupante: la búsqueda del difícil equilibrio entre el interés por las personas tal como son y el interés por las personas tal como podrían ser, entre las identidades que tenemos y las que podríamos alcanzar (Bernal, 2011). O sea, la necesidad de hallar equilibrio entre nuestras preferencias desnudas y las "informadas". Si se ignoran las primeras, se cae en la tiranía; si se menosprecian las segundas, se cae en el derrotismo o la mera complacencia (Appiah, 2007).

Las instituciones educativas, como instituciones específicas de educación, han de establecer sin ambages su compromiso con la profunda tarea de educar, con su inestimable labor de ayuda a la formación en y para la autonomía y la responsabilidad. "Si ha existido alguna vez una función social que tenga consecuencias globales para todo el género humano ésa es la educación", nos dice Michael Fullan (2002, 285-286) animándonos a emprender procesos de cambio educativo en una espiral de "identidad hacia el exterior", camino hacia el progreso personal y social: el cambio a gran escala no se logrará si el profesorado se identifica sólo con su aula y no se preocupa igualmente por el éxito de los otros profesores y del conjunto de la escuela, si los directores sólo se preocupan por su escuela y no por los otros directores y el conjunto de escuelas o si los Estados se identifican sólo con sus propios Estados y no se preocupan por el éxito de otros Estados. Los nuevos significados del cambio en la educación podrían cifrarse en la búsqueda de sentido y de compromiso. Nadie está excluido de este reto. 
Precisamos, en este sentido, de ingentes esfuerzos resignificadores de la cultura (curricular, profesional, política...), de una profunda reconceptualización pedagógica de los espacios y de una considerable reestructuración del tiempo. No olvidemos que la educación, en última instancia, como dice Bauman (2007b), es tiempo. Precisamos, pues, contemplar el profundo valor de la educación como tiempo, como tiempos distintos y divergentes. Difícilmente se llegará al descubrimiento de sentido y al establecimiento de compromiso si no se dispone del tiempo adecuado. Aquí, frente a la prisa de la vida que caracteriza nuestra época, tenemos otro desafío estructural que compromete a la sociedad toda y no sólo a los sistemas educativos. Las respuestas a estos retos reclaman el ejercicio pleno de nuestra autonomía y responsabilidad.

\section{REFERENCIAS BIBLIOGRÁFICAS}

Appiah, K. A. (2007) La ética de la identidad. Buenos Aires, Katz.

AREnAS, L. (2002) Identidad y subjetividad. Materiales para una historia de la filosofía moderna. Madrid, Biblioteca Nueva.

BÁrcena, F. (2003) Sobre el porvenir de la educación moral, en Ruiz Corbella, M. (coord.) Educación moral: aprender a ser, aprender a convivir. Barcelona, Ariel, 91-115.

BÁrCENA, F. y MÈLICH, J. C. (1999) La palabra del otro. Una crítica del principio de autonomía en educación. Revista Española de Pedagogía, 214, 465-484.

BaUman, Z. (2007a) Libertad. Buenos Aires, Losada.

- (2007b) Los retos de la educación en la modernidad líquida. Barcelona, Gedisa.

BERLIN, I. (2004) Sobre la libertad. Madrid, Alianza Editorial.

Bernal, A. (2005) Reconceptualización de la identidad personal y educación para la autodeterminación posible. Teoría de la Educación. Revista Interuniversitaria, 17, 97-128.

- (2011) Postmodernización y educación. Notas para el debate de una narrativa pedagógica centrada en la identidad. Educación XXI, 14 (2), 285-302.

BRUner, J. (1991) Actos de significado. Más allá de la revolución cognitiva. Madrid, Alianza.

- (2000) La educación, puerta de la cultura. Madrid, Visor.

CAPAFOns, A. et al. (1985) Autocontrol y Educación. Valencia, Nau-Llibres.

Cortina, A. (1998) Hasta un pueblo de demonios. Ética pública y sociedad. Madrid, Taurus.

- (2001) El protagonismo de los ciudadanos. Dimensiones de la ciudadanía, en CoRTina, A. y Conill, J. (coords.) Educar en la ciudadanía. Valencia, Institució Alfons el Magnànim, 13-30.

- (2009) Las fronteras de la persona. El valor de los animales, la dignidad de las personas. Madrid, Taurus.

CuYPERS, S. E. (2010) Autonomy in R. S. Peters Educational Theory. Journal of Philosophy of Education, 43 (1), 189-207.

Damasio, A. (2010) Y el cerebro creó al hombre. Barcelona, Destino.

DennetT, D. C. (2004) La evolución de la libertad. Barcelona, Paidós.

DERRIDA, J. (1994) Márgenes de la filosofía. Madrid, Cátedra.

DÍAZ DE IPARRAGUIRRE, A. (2008) La responsabilidad social de la universidad en la promoción del capital social para el desarrollo sustentable. Consultado el 19 de marzo de 2010. http://www.eumed.net/libros/2008b/402/LA\%20RESPONSABILIDAD\%20SOCIAL\%20 
MARTA RUIZ CORBELLA, ANTONIO BERNAL GUERRERO, FERNANDO GIL CANTERO Y JUAN ESCÁMEZ SÁNCHEZ

SER UNO MISMO. REPENSANDO LA AUTONOMÍA Y LA RESPONSABILIDAD...

DE\%20LA\%20UNIVERSIDAD\%20EN\%20LA\%20PROMOCION\%20DEL\%20CAPITAL\%20 SOCIAL\%20PARA\%20EL\%20DESARROLLO\%20SUSTENTABLE\%20RESUMEN.htm.

DuBAR, C. (2002) La crisis de las identidades. La interpretación de una mutación. Barcelona, Bellaterra.

DuRKHEIM, E. (1974) Educación y sociología. Buenos Aires, Schapire (ed. original: Education et sociologie. París, 1922).

EsCÁmez, J. (2003) La educación para la participación en la sociedad civil. Revista de Educación, n. ${ }^{\circ}$ extraordinario Ciudadanía y Educación, 191-211.

- (2008) La formación de la responsabilidad, objetivo prioritario de la educación, en TOURIÑÁn, J. M. (dir.) Educación en valores, educación intercultural y formación para la convivencia pacífica. La Coruña, Netbiblo, 170-185.

EscÁmez, J. y Gil MARTínez, R. (2001) La educación en la responsabilidad. Barcelona, Paidós. FIerro, A. (2002) Personalidad, persona, acción. Un tratado de psicología. Madrid, Alianza. Fullan, M. (2002) Los nuevos significados del cambio en la educación. Barcelona, Octaedro. García Carrasco, J. (2007) Leer en la cara y en el mundo. Barcelona, Herder.

García del Dujo, Á.; García Carrasco, J. y Asensio, J. M. (2006) Hechos y pensamientos sobre educación en busca de una teoría: la trama entre biología, tecnología y cultura. Revista Portuguesa de Pedagogía, 40 (1), 197-221.

Giddens, A. (1997) Modernidad e identidad del yo. Barcelona, Península.

Gil Cantero, F. (2008) Ciudadanía y humanidad. La educación en el disenso. Teoría de la Educación. Revista Interuniversitaria, 20, 25-44.

LÉvinas, E. (2001) Entre nosotros. Ensayos para pensar en otro. Valencia, Pretextos.

Macintyre, A. (2001) Animales racionales y dependientes. Por qué los seres humanos necesitamos las virtudes. Barcelona, Paidós.

Metzinger, T. (2003) Being No One. The Self-Model Theory of Subjectivity. Cambridge MA, MIT Press.

Millán Puelles, A. (1967) La estructura de la subjetividad. Madrid, Rialp.

Novo, M. (2007) El desarrollo sostenible. Su dimensión ambiental y educativa. Madrid, UNESCO-Prentice Hall.

ORTEGA, P. (2010) Educar es responder a la pregunta del otro. Edetania, 37, 13-31.

Ortega, P.; Touriñán, J. M. y Escámez, J. (2007) La educación ciudadana en una sociedad multicultural y compleja, en BOAVIDA, J. y GARCía DEL Dujo, Á. Teoría da educação. Contributos Ibéricos. Coimbra, Universidade de Coimbra, 493-527.

Peces-Barba, G. (dir.) (1987) Derecho positivo de los derechos humanos. Madrid, Debate.

Piaget, J. (1948) Où va l'éducation. Paris, unesco-Denoël/Gonthier.

SCHMÜCKer, R. y STEInVorth, U. (eds.) (2002) Gerechtigkeit und Politik. Philosophische Perspektiven. Berlín, Akademie Verlag.

SCHNEEWIND, J. B. (2010) La Invención de la autonomía: una historia de la filosofía moral moderna. México, FCE.

SEARLE, J. R. (2000) Razones para actuar. Oviedo, Nobel.

SEN, A. (2007) Identidad y violencia. La ilusión del destino. Buenos Aires, Katz.

TAYLOR, Ch. (1994) La ética de la autenticidad. Barcelona, Paidós.

- (1996) Las fuentes del yo. La construcción de la identidad moderna. Barcelona, Paidós.

- (1997) Argumentos filosóficos: ensayos sobre el conocimiento, el lenguaje y la modernidad. Barcelona, Paidós.

Touraine, A. (2009) La mirada social. Barcelona, Paidós. 